\title{
Evaluation of Pre-Service Teacher Preparation for Achieving the National Standards for Beginning Physical Education Teachers
}

\author{
Weiyun Chen
}

Received: 13 December 2004 / Revised: 19 October 2005 / Accepted: 19 October 2005

(C) Springer Science + Business Media, Inc. 2006

\begin{abstract}
The aim of this study was to investigate pre-service physical education teachers' self-assessment of their competent levels in achieving the national standards for beginning physical education teachers (National Association for Sport and Physical Education (NASPE), 1995). One hundred seventy-three pre-service teachers in 10 physical education teacher education programs completed the Achieving the NASPE Standards Inventory (ANSI) that was developed and validated for the purpose of this study. The results indicated that the ANSI provided reliable and valid information about discerning pre-service teachers' self-assessment of their overall and specific competence in achieving the standards within the continuum from unacceptable to competent levels.
\end{abstract}

Keywords NASPE beginning teacher standards $\cdot$ knowledge $\cdot$ skills $\cdot$ disposals

High quality learning demands highly qualified teachers. How to prepare qualified teachers had become the central stage of the educational reform movement. Teacher preparation plays a key role in equipping pre-service teachers with essential knowledge, skills, and dispositions for a quality teaching (Darling-Hammond, 2001, 2004; Delandshere \& Arens, 2001). To ensure teacher preparation to meet the needs of the reform, the Interstate New Teacher-Assessment and Support Consortium (INTASC), coalescing with the National Board Professional Teaching Standards (NBPTS) and the National Council for the Accreditation of Teacher Education (NCATE), developed the common core standards for beginning teachers (DarlingHammond, 2001; Delandshere \& Arens, 2001).

\footnotetext{
W. Chen (๘)

Division of Kinesiology,

University of Michigan,

401 Washtenaw Avenue, Ann Arbor, MI 48109-2214, USA

e-mail: chenwy@umich.edu
} 


\section{Background}

The primary purpose of this study was to investigate pre-service physical education teachers' self-assessment of their competent levels in achieving the NASPE beginning teacher standards. The secondary purpose of this study was to develop and validate the Achieving the NASPE Standards Inventory (ANSI) in support of the main purpose of this study. The INTASC standards provide a targeted direction for strengthening teacher education programs. The INTASC task force initially developed 10 overarching principles that provided the basis for designing subject-specific teaching standards (Darling-Hammond, 2001; Delandshere \& Petrosky, 2004). The 10 key principles reflect the core tenets of effective teaching. Coupled with the essential principles, INTASC designed 10 common core standards upon which beginning teachers should be prepared. They articulate what all beginning teachers should know, be able to do, and value in three unique but interrelated components: knowledge, skills, and dispositions. The INTASC standards are directly linked to K-12 content standards (Darling-Hammond, 2001; Delandshere \& Arens, 2001).

Using the INTASC standards as a guide, The National Association for Sports and Physical Education (NASPE) developed the National Standards for Beginning Physical Education Teachers (NASPE, 1995). The NASPE beginning teacher standards provide targeted goals and objectives for preparing prospective physical education teachers (NASPE, 1995, 2003). The NASPE beginning teacher standards define what the beginning teacher should value about, have knowledge of, and demonstrate an understanding of (a) physical education content and disciplinerelated concepts; (b) how an individual's growth and development affects the students' learning in physical education settings; (c) how individuals differ in terms of skill, cognitive, social, emotional, and cultural aspects and how to meet the students' diverse needs; (d) providing students with a positive and productive learning environment to motivate their active engagement in learning; (e) using effective communication skills to enhance the students' learning; (f) planning developmentally appropriate learning experiences and using appropriate instructional strategies to facilitate the students' ability to achieve instructional objectives; (g) assessing, analyzing, and monitoring students' movement performance, cognitive understanding, and social development; (h) engaging in self-reflective practice to continually hone teaching skills; (i) applying current technology into learning and teaching processes; and ( $\mathrm{j}$ ) working collaboratively with colleagues, parents, and communities to support the students' learning. Similar to the INTASC standards, each of the 10 NASPE standards articulates three interrelated essential components: knowledge, performance, and dispositions. Knowledge refers to the subject matter the beginning teacher needs to conceptually know and understand. Performance represents the pedagogical skills necessary for effectively teaching the subject matter to students in K-12. Dispositions identify what the beginning teacher should value about physical education learning and teaching (NASPE, 1995).

\section{Previous Research}

The NASPE beginning teacher standards serve as a consensus-based guide and direction for teacher educators to configure or revamp their teacher education programs for meeting the new challenge (NASPE, 1995, 2003). To help students succeed in 
meeting the K-12 content standards, it is critical for teacher education programs to equip pre-service teachers with a deep knowledge of the subject matter (Laczko-Kerr \& Berliner, 2002; Rovegno, 1998; Wilson et al., 2001). A body of research shows that teachers' knowledge of subject matter is directly linked to their teaching performance and students learning. For example, Hastie \& Vlaisavljevic (1999) reported that physical education teachers with strong content knowledge base created a higher level of responsible and productive learning environment for students to engage in more instructional tasks, compared to those with weak content knowledge base. The study by Goldhaber \& Brewer (2000) indicated that the students taught by teachers having bachelors or master degrees in mathematics had higher test scores than students who had teachers without these degrees. Beginning teachers must develop a solid knowledge base of subject matter necessary for providing quality learning.

To ensure that students attain high achievement, teacher education programs must prepare beginning teachers with strong pedagogical knowledge and skills necessary for effective teachers (Darling-Hammond \& Ball, 2004; Laczko-Kerr \& Berliner, 2002; Rovegno, 1998). Studies reveal that teachers' pedagogical preparation is an important contributor to effective teaching practices. For instance, Walkwitz \& Lee (1992) noted that during practice, students taught by teachers who had training in teaching manipulative skills demonstrated more mature levels of throwing than those taught by teachers with no such training. Similarly, Monk (1994) reported that students who had teachers with more math and science teaching methods and pedagogy preparation were more likely to show better test outcomes in math and science, compared to students having teachers with a lack of pedagogical preparation. Teachers' pedagogical knowledge and teaching skills greatly impact how teachers teach subject matter to students for meaning and understanding (Darling-Hammond, 2000; Rovegno, 1998).

To positively affect students' motivation, growth, and learning, teacher education programs should also foster pre-service teachers to value the subjects they teach and the teaching profession, to be committed to their students and teaching, and to have professional ethics (Chen \& Rovegno, 2000; Darling-Hammond, 2000; Rovegno, 1998). Studies indicate that teachers' values, commitments, and ethics strongly impacted how they taught subjects to students, how they treated their students, and how they pursued their own professional growth and development. For example, the study by Chen \& Rovegno (2000) indicated that teachers who believed a constructivist view of learning engaged their students in using self-regulation, critical thinking, and social cooperation while learning movement tasks. Likewise, Hammrich (1998) found that teacher candidates holding a constructivist view of science teaching engaged students in using their thinking skills and facilitating their understanding about information as opposed to having students memorize facts and events. Teachers' dispositions influence how teachers use and apply their knowledge and teaching skills in teaching practices (Darling-Hammond, 2000; Rovegno, 1998).

The NASPE beginning teacher standards (1995) have existed for nine years. However, little is known about how well physical education teacher education programs prepare their pre-service teachers for acquiring a foundation of knowledge, skills, and dispositions. Recent research supports the notion that selfassessment serve as one of practical measuring tools for assessing teachers' performance in achieving the teaching standards (Blank, 2002; Mullens, 1998). Comparing self-report survey data collection with observation of classes and logs data collection, Mullens (1998) reported that the self-report data were highly 
correlated with the results collected from observation of classes and daily log. Similarly, Blank (2002) examined the use of survey enacted-curriculum analyzed teachers' classroom practice and self-report data. The findings indicated that selfreport survey provided reliable and comparable data on discerning teachers' instruction practices in alignment with the teaching standards for math and science education. Thus, this study only focuses on using pre-service teachers as the key agents for self-assessing how competent they feel about their core teaching skills, knowledge, and dispositions addressed in the NASPE beginning teachers standards. This study is significant in three ways: First, this study provides a profile of whether teacher education programs are aligned with the beginning teacher standards from pre-service teachers' perspectives. Next, this study presents insights about the teacher education programs' strengths and weaknesses in relation to meeting the standards. Last, this study provides a valid and reliable instrument that can be used for a future study.

\section{Methods}

\section{Instrumentation}

The ANSI items and its major theoretical constructs were adapted from the NASPE beginning teacher standards (1995). To ensure that each item clearly reflects a specific theoretical construct and a specific standard, the author modified items directly from items elaborated on three constructs under each standard. Items that were modified from the conceptual construct of Dispositions were prefaced with the heading "I seek to ...." and "It is important to ...." While items centering on the theoretical construct of Knowledge were prefaced with the heading "I have knowledge of ...." The items reflecting the theoretical construct of Performance were using different action verbs depending on specific standard such as "I demonstrated ...." and "I provided ...." and so on. The ANSI, as a self-assessment instrument, was designed for pre-service physical education teachers to self-evaluate how well they felt they were prepared for meeting the NASPE beginning teacher standards. In other words, the ANSI was used to discern pre-service teachers' perceptions of their preparations for what they should know, be able to do, and value.

To ensure the reliability, validity, and feasibility of the ANSI, a pilot study was conducted with a sample pool of 108 subjects who did not participate in the main study using the 78-item ANSI. The subjects who enrolled in four different physical education teacher education programs in a northeastern state were selected on a voluntary basis. The resultant ANSI yielded three factors that supported the theoretical constructs of the inventory. Subsequently, the 78-item ANSI was sent to four pedagogical scholars in the field of physical education. All the pedagogical scholars (a) have been teacher educators for more than 10 years, (b) have been well known for their research and scholarly activities in the field of physical education pedagogy, (c) have used the standards as their teacher education program goals for preparing their pre-service teachers, and (d) have conducted research related to the standards or published article(s) discussing the application of the standards in teaching. The four scholars were asked to make judgement about whether and to what degree the items on the ANSI reflected theoretical constructs of Disposition, 
Knowledge, and Performance in the NASPE beginning teacher standards. Based on the four scholars' evaluation, comments, and suggestions, the author deleted redundant and vague items and then revised the remainders of the ANSI repeatedly. Additionally, the author re-wrote and revised items of the ANSI numerous times according to the second edition of the NASPE standards. Finally, the revised ANSI consisted of two parts: demographic information and 45 items rated on a five-point rating scale that ranged from (5 absolutely true) to 1 (not true at all).

\section{Participants and Procedures}

The participants for this study were 173 PETE pre-service teachers (76 male and 97 female) from 10 PETE programs at 10 state universities that were located in northeastern, southeastern, midwestern, northwestern, and southern districts in the United States. The mean age of the participants was 24 years, while the range was from 20-41 years. Of the 173 pre-service teachers, four $(2.3 \%)$ were sophomore students, $47(27.2 \%)$ were junior students, 56 (32.4\%) were senior students (not student teachers yet), and $66(38.2 \%)$ were student teachers. In terms of race/ ethnicity, $89.6 \%$ were White (non-Hispanic), $4 \%$ were Hispanic, $5.2 \%$ were African-American, $0.6 \%$ were Asian-American, and $0.6 \%$ were Native American. The participants were selected by using cluster random sampling methods (Hinkle et al., 1994). Initially, a directory of PETE educators was obtained from the AERA SIG web site. Next, 15 PETE teacher educators from the list were randomly chosen. 10 teacher educators granted permission to conduct the study. The author sent them copies of the inventory and of the consent form along with the letter indicating the protocols for completing the inventory. The protocols included that the teacher educator: (a) could ask PETE juniors, seniors, or student teachers to participate in this study on a voluntary basis; (b) announced the purpose of the study and directions for filling out the inventory; (c) asked the voluntary participants to fill out the inventory either during the class meeting or outside the class meeting; and (d) collected the completed inventories and mailed them back to the author. One hundred seventy-three pre-service teachers anonymously completed the inventory that indicated that they voluntarily participated in the study and/or signed the consent form.

\section{Data Analysis}

The internal consistency reliability of the inventory was assessed using Cronbach alpha reliability and an item-to-total correlation coefficient to analyze the data of 173 cases. The construct-related validity of the inventory and the underlying dimensions (sub-scales of the ANSI) were examined by means of a principal component analysis. The than one and the meaning of items. The strength of the relationship between the total scale and the sub-scales of the ANSI was examined by using Pearson product correlation coefficients.

The differences on the mean scores of the total scale of the ANSI among 10 groups were examined by a one-way analysis of variance (ANOVA). In addition, the differences on the mean scores of the total scale of the ANSI among years of college (e.g., sophomore, junior, senior not student teachers, student teachers) were also examined by a one-way analysis of variance (ANOVA). Group differences of the three factors (sub-scales) of the ANSI were analyzed using MANOVA, a follow- 
up ANOVA, and the post hoc Dunn (Bonferroni) multiple comparison statistical methods. The composite score of each factor was calculated by summing each score of the items clustered on that factor. To identify levels of competence in achieving the NASPE beginning teacher standards, (Burry-Stock, 1995) methods of percentage requirement, a quasi-distribution, was used for this study. According to BurryStock's methods (1995), four levels of achieving the standards were identified and quantified: (a) Competent Level (85-99\%), (b) Acceptable Level (70-84\%), (c) Developing Level (35-69\%), and (d) Unacceptable Level (1-34\%).

\section{Results}

\section{Psychometric Properties of the ANSI}

Reliability of the ANSI. The means, standard deviations, Cronbach alpha reliability coefficient for the total scale and three sub-scales of the ANSI are presented in Table 1. The alpha reliability coefficient of the ANSI was 0.93 for the total scale, indicating a high degree of measurement reliability. The total scale of the ANSI represents the unitary measurement of pre-service teachers' self-assessment of competence in achieving the NASPE beginning teacher standards as a whole. Furthermore, in this study, three sub-scales (factors) produced by using a principal component analysis represented three major constructs of the ANSI. So, each factor of the alpha reliability coefficients was also considered. The Cronbach alpha reliability coefficient of the three sub-scales (factors) ranged from 0.82 to 0.89 . The results indicated that each factor had high degree of internal consistency reliability. Two items (item 35 and item 44) were deleted because the item-to-total correlation coefficients were below 0.35 . The resultant 43 item-to-total correlation coefficients were 0.38 or above with the highest one being 0.68 . The results supported the high internal consistency of the inventory. Pearson product correlation coefficients are presented in Table 2. As shown in Table 3, there was a strong relationship between each of the three sub-scales and the total scale of the ANSI. All of the correlation coefficients were statistically significant at the $\mathrm{p}<.01$ level. The correlations among the subscales of the ANSI that were characterized as a moderate relationship were also statistically significant at the $\mathrm{p}<.01$ level. The results indicated that the three sub-scales contributed to the total scale of the ANSI and each sub-scale assessed distinct but interrelated construct of the ANSI.

Validity of the ANSI. A three-factor solution was generated from the principal component analysis with a varimax rotation based on the criteria of eigenvalues

Table 1 Means, standard deviations, and Cronbach alpha reliability coefficients for the total scale of and the sub-scales of the ANSI

\begin{tabular}{lrrr}
\hline Variables & M & SD & R \\
\hline Total scale & 185.9 & 17.9 & 0.93 \\
Sub-scale (Factor 1) & 40.4 & 3.8 & 0.82 \\
Sub-scale (Factor 2) & 74.7 & 8.3 & 0.89 \\
Sub-scale (Factor 3) & 67.6 & 7.8 & 0.88 \\
\hline
\end{tabular}


Table 2 Means, standard deviations, and Pearson product moment correlation coefficients for ANSI sub-scales and the total scale

\begin{tabular}{lcccr}
\hline Variables & Sub-scale 1 & Sub-scale 2 & Sub-scale 3 & Total scale \\
\hline Sub-scale 1 & 1.00 & & & \\
Sub-scale 2 & $.67^{* *}$ & & & \\
Sub-scale 3 & $.53^{* *}$ & $.67^{* *}$ & & \\
Total scale & $.75^{* *}$ & $.90^{* *}$ & $.88^{* *}$ & \\
Variable mean & 40.38 & 74.77 & 67.56 & 190.45 \\
Variable SD & 3.83 & 8.33 & 7.79 & 18.09 \\
\hline
\end{tabular}

Note: ** represents correlation is significant at the 0.01 level (2-tailed)

greater than 1 and inspection of scree plot. The three factors accounted for $43 \%$ of the total variance, contributing to the construct-related validity. The items and their factor loadings are presented in Table 3. The 43 items on the ANSI were classified into three sub-scales (factors) based on the factor loadings and the meaning of the items. Some items that had cross-loadings such as items 9, 20, 25, 26, and 28 were grouped into one factor based on the criterion of matching the meaning of items to the construct of the sub-scale (factor). For example, item 25 had a factor loading of 0.49 on Factor 1 and also had a factor loading of 0.46 on Factor 2. This item was grouped into Factor 2 instead of Factor 1 because the meaning of the item reflected assessing a teacher's pedagogical knowledge and skills instead of assessing dispositions of teaching.

Based on the meaning of items that clustered together, Factor 1 was named Dispositions of Pedagogy. Nine items loading on Factor 1 focused on assessing a pre-service teacher's values and beliefs about importance of accommodating individuals' differences, creating positive learning environment, integrating assessment into teaching, planning, and reflection on teaching. Factor 2 was labeled Pedagogical Knowledge and Skills. Factor 2 consisting of 18 items centered on assessing a pre-service teacher's pedagogical skills and knowledge of students' growth and development, diverse learners, class management and motivation, communication, assessment, self-reflection, technology, and collaboration. Factor 3 was named Knowledge, Abilities, and Dispositions of Subject Matter. Factor 3 was composed of 16 items that measured a pre-service teacher's understanding of subject matter, ability to use knowledge of the subject matter in teaching, and values and beliefs about the importance of subject matter knowledge and abilities to teaching.

\section{Group Differences of Overall Competence in Achieving the NASPE Standards}

A pre-service teacher's total score on 43-items of the ANSI was the indicator of his/ her overall competence in achieving the beginning teacher standards. The preservice teacher's overall competence in achieving the standards was then quantified into four levels based on a quasi-distribution (Burry-Stock, 1995). Table 4 shows the descriptive statistics and levels of achieving the standards for 10 groups. From Table 4, the mean score for the overall group is 183 with a standard deviation of 17.4. Across all groups, Group 9 had the highest mean score of 189, while the mean score 
Table 3 Items and their factor loadings produced by a principal component analysis with a varimax rotation

Items

Factor loadings

$1 \quad 2 \quad 3$

Disposition of Pedagogy

10. Developmental stages influence students learning motor skills.

$\begin{array}{rrr}.48 & .24 & .33 \\ .30 & .37 & .30 \\ & & \\ .70 & .05 & .05 \\ .75 & -.03 & .15 \\ .67 & -.06 & .23 \\ .50 & .40 & .05 \\ .69 & .06 & -.05 \\ .59 & .07 & .19 \\ .58 & .25 & -.03 \\ & & \\ .09 & .37 & .25 \\ & & \\ .42 & .22 & .19 \\ .43 & .45 & .11 \\ .43 & .53 & .09\end{array}$

13. I seek to understand learners' cultural values related to physical activity.

15. It is important to appreciate individual differences in learning. .05

18. It is important to establish a positive learning environment for students.

21. Planning is important to achieving instructional objectives.

24. Students assessment is enhancing students learning.

29. It is important to self-reflect on my own teaching.

32. It is important to adapt lesson plans to changing circumstances

45. I seek to improve my subject matter knowledge.

Pedagogical Knowledge and Skills

19. I provided students with opportunities to choose their levels of performance.

20. I encouraged students to respect for their peers' individual differences.

22. I have knowledge of accommodating individuals' differences.

23. I used instructional strategies to promote students' responsible behaviors.

25. I have knowledge of maintaining appropriate student behaviors.

26. I smoothly organized students, space, and equipment for learning activities.

27. I have knowledge of creative productive learning environment for students.

28. I provided students with maximal participation and learning time.

31. I used various communication skills to facilitate students understanding.

33. I selected instructional strategies based on lesson content and students' needs.

34. I stated instructional objectives based on students' skill levels.

37. I revised my teaching practices based on students' movement responses.

38. I provided students with feedback about their performance and progress.

39. I used appropriate assessment tools to evaluate students' motor performance.

40. I have knowledge of technologies and the applications to physical $\quad \begin{array}{lllll} & -.07 & .61 & .32\end{array}$ education.

41. I used appropriate assessment tools to evaluate students' behaviors.

42. I have knowledge of how school functions within the large community.

43. I incorporated technology into my curriculum and teaching.

$\begin{array}{lll}.49 & .46 & .15\end{array}$

$\begin{array}{lll}.47 & .43 & .19\end{array}$

$\begin{array}{lll}.46 & .51 & .25\end{array}$

$\begin{array}{lll}.52 & .42 & .14\end{array}$

$\begin{array}{lll}.36 & .50 & .14\end{array}$

$.25 \quad .48 \quad .25$

$\begin{array}{lll}.20 & .47 & .41\end{array}$

$\begin{array}{lll}.01 & .45 & .46\end{array}$

$\begin{array}{lll}.14 & .48 & .19\end{array}$

$.09 \quad .56 \quad .43$

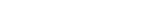

.06

$\begin{array}{rrr}.09 & .70 & .06 \\ .12 & .71 & .01\end{array}$

$.01 \quad .66-.04$

Knowledge, Ability, and Disposition of subject matter

1. I seek to learn various physical education contents in-depth.

2. I have knowledge of critical elements of various motor skills.

$\begin{array}{lll}.14 & -.03 & .52\end{array}$

$\begin{array}{lll}-.05 & .07 & .74\end{array}$

3. I demonstrated competence in teaching motor skills.

$\begin{array}{lll}.01 & .26 & .67\end{array}$

4. I seek to keep abreast of new ideas in physical education. $\quad \begin{array}{rrr}.06 & .57\end{array}$

5. I have knowledge of fitness concepts and principles. $\quad-.03 \quad \begin{array}{lll}.18 & .65\end{array}$

6. I applied bioscience concepts and principles to teaching motor skills. $\begin{array}{llll}-.11 & .36 & .46\end{array}$ 
Table 3 (continued)

Items

Factor loadings

1

2

3

7. I seek to help learners become physically educated persons.

$\begin{array}{ccc}.38 & .19 & .56 \\ .22 & .43 & .43 \\ & & \\ .54 & .28 & .39 \\ .32 & .09 & .47 \\ & & \\ .12 & .15 & .65 \\ .35 & .17 & .44 \\ .29 & -.01 & .51 \\ & & \\ .17 & .22 & .61 \\ .25 & .38 & .47 \\ .31 & .35 & .38 \\ 29 & 7.4 & 5.9\end{array}$

of 179 in Group 1, the mean score of 164 in Group 6, and the mean score of 181 in Group 10 were lower than that of overall group.

According to Burry-Stock's methods (1995), four levels of achieving the standards were identified and quantified: (a) Competent Level (85-99\%), (b) Acceptable Level (70-84\%), (c) Developing Level (35-69\%), and (d) Unacceptable Level (1$34 \%$ ). The results of percentage quantification indicated that the pre-service teachers in Group 2, 3, 4, 5, 7, 8, and 9 were in the Competent Level because these groups' percentage of the total scale was $85 \%$ or above. In contrast, the pre-service teachers in Group 1, 6, and 10 were classified into Acceptable Level because the three groups' percentage of the total scale was $83 \%, 76 \%$, and $84 \%$, respectively.

The ANOVA revealed a significant difference on the mean scores of the total scale among the groups $(\mathrm{F} 9,163=2.678, \mathrm{p}<0.01)$. The results of a follow-up Dunn (Bonferroni) multiple comparison analysis indicated that the pre-service teachers in Group 2, 4, 7, and 9 self-assessed their achievement of the NASPE standards to be significantly higher than those in Group 6 did on the ANSI $(p<.05)$. No significant difference was found for the remainders of the comparison. In contrast, the ANOVA revealed no significant difference on the mean scores of the total scale among years of college $(\mathrm{F} 3,169=1.616, \mathrm{p}>0.05)$.

\section{Group Differences of Competence in Three Sub-Scales of the ANSI}

To examine group differences on the three sub-scales (factors) of ANSI, a one-way multivariate analysis of variance (MANOVA) was conducted on the mean scores of the three factors that emerged from a principal component analysis. The results of the MANOVA analysis revealed an overall significant difference in the mean scores of the three factors among the 10 groups (Wilks' $=0.74, \mathrm{F9}, 163=1.92, \mathrm{p}<0.01$ ). Table 5 presents the mean scores of and standard deviations of the three factors as well as levels of achieving the standards on three factors among the 10 groups. 
Table 4 Descriptive statistics and levels of achieving the standards for 10 groups (maximum score is 215)

\begin{tabular}{llllll}
\hline Groups & N & M & SD & Levels & $\%$ \\
\hline 1 & 15 & 179.47 & 18.7 & Acceptable & 83 \\
2 & 16 & 184.19 & 19.25 & Competent & 86 \\
3 & 21 & 183.14 & 15.73 & Competent & 85 \\
4 & 19 & 185.11 & 10.2 & Competent & 86 \\
5 & 17 & 183.41 & 16.58 & Competent & 85 \\
6 & 14 & 164.16 & 25.82 & Acceptable & 76 \\
7 & 13 & 185.46 & 13.53 & Competent & 86 \\
8 & 10 & 183.80 & 15.65 & Competent & 85 \\
9 & 31 & 189.39 & 15.08 & Competent & 88 \\
10 & 17 & 180.59 & 15.31 & Acceptable & 84 \\
Total & 173 & 182 & 17.38 & Competent & 85 \\
\hline
\end{tabular}

Regarding Factor 1: Disposition of Pedagogy, all groups were classified into Competent Level, except for Group 6 categorized into Acceptable Level based on the percentage requirement. A follow-up ANOVA analysis revealed a significant difference of the mean scores on Factor 1 among the 10 groups $(F 9,163=1.95, \mathrm{p}<$ 0.05). Subsequently, the Dunn (Bonferroni) multiple comparisons revealed a significant difference on the mean scores of Factor 1 between Group 9 and Group 6 (42 vs. $38, \mathrm{p}=.05$ ). The results indicated that the pre-service teachers in Group 9 scored significantly higher than those in Group 6. No significant difference on Factor $1(\mathrm{p}>.05)$ was found for the rest of the comparisons.

With respect to Factor 2: Pedagogical Knowledge and Skills, only Group 2, 4, 5 , and 9 were grouped into the Competent Level, while the rest of the groups belonged to the Acceptable level according to the percentage requirement. A follow-up ANOVA analysis yielded a significant difference of the mean scores on Factor 2 among the 10 groups $(\mathrm{F} 9,163=2.54, \mathrm{p}<.01)$. The Dunn (Bonferroni) multiple comparison analysis found a significant difference of the mean scores between Group 5 and Group $6(77.18$ vs. 67.07, p <.05) as well as between Group 9 and Group 6 (77.45 vs. 67.07, $\mathrm{p}<.05)$. The other comparisons found no significant difference. The results indicated that the pre-service teachers in Group 5 and Group 9 self-assessed the level of exhibiting pedagogical knowledge and skills significantly higher than those in Group 6.

Concerning Factor 3: Knowledge, Ability, and Disposition of Subject Matter, six groups were categorized into the Competent Level. They are Groups 2, 3, 7, 8, 9, and 10. Conversely, Group 1, 4, 5, and 6 were classified into the Acceptable level. A follow-up ANOVA analysis produced a significant difference of the mean scores on Factor 3 among the 10 groups $(\mathrm{F} 9,163=2.45, \mathrm{p}<.01)$. According to the Dunn (Bonferroni) multiple comparison analysis, the comparisons of Group 3 with Group 6 (68.57 vs. 59.09 p < .05) and Group 9 with Group 6 (69.94 vs. 59.09, $\mathrm{p}<.01)$ were significantly different. In contrast, there was no significant difference of the mean scores for the other comparisons. The results illustrated that the pre-service teachers in Group 3 and Group 9 self-assessed their competence in demonstrating knowledge, ability, and disposition of subject matter was significantly higher than did those in Group 6. 
Table 5 The mean scores of and standard deviations of the three sub-scales as well as levels of achieving the standards on three sub-scales among the 10 groups

\begin{tabular}{llllll}
\hline Groups & N & M & SD & Levels & $\%$ \\
\hline
\end{tabular}

Factor 1: Dispositions of Pedagogy (9 items with maximum score of 45)

$\begin{array}{llllll}1 & 15 & 39.67 & 5.46 & \text { Competent } & 88 \\ 2 & 16 & 39.44 & 4.43 & \text { Competent } & 88 \\ 3 & 21 & 40.33 & 2.76 & \text { Competent } & 90 \\ 4 & 19 & 41.63 & 2.93 & \text { Competent } & 93 \\ 5 & 17 & 39.12 & 3.57 & \text { Competent } & 87 \\ 6 & 14 & 38.00 & 5.96 & \text { Acceptable } & 84 \\ 7 & 13 & 40.69 & 3.33 & \text { Competent } & 90 \\ 8 & 10 & 41 & 2.31 & \text { Competent } & 91 \\ 9 & 31 & 42 & 2.94 & \text { Competent } & 93 \\ 10 & 17 & 40.18 & 3.11 & \text { Competent } & 89\end{array}$

Factor 2: Pedagogical Knowledge and Skills (18 items with maximum score of 90)

$\begin{array}{llllll}1 & 15 & 72.53 & 8.29 & \text { Acceptable } & 81 \\ 2 & 16 & 76.69 & 9.52 & \text { Competent } & 85 \\ 3 & 21 & 74.24 & 8.23 & \text { Acceptable } & 82 \\ 4 & 19 & 76.21 & 6.00 & \text { Competent } & 85 \\ 5 & 17 & 77.18 & 5.86 & \text { Competent } & 86 \\ 6 & 14 & 67.07 & 11.54 & \text { Acceptable } & 75 \\ 7 & 13 & 76.38 & 6.06 & \text { Acceptable } & 85 \\ 8 & 10 & 73.80 & 8.67 & \text { Acceptable } & 82 \\ 9 & 31 & 77.45 & 7.72 & \text { Competent } & 86 \\ 10 & 17 & 72.41 & 7.80 & \text { Acceptable } & 80\end{array}$

Factor 3: Knowledge, Ability, and Disposition of Subject Matter (16 items with maximum score of 80)

\begin{tabular}{lllrll}
1 & 15 & 67.27 & 7.09 & Acceptable & 84 \\
2 & 16 & 68.06 & 7.15 & Competent & 85 \\
3 & 21 & 68.57 & 7.04 & Competent & 86 \\
4 & 19 & 67.26 & 6.14 & Acceptable & 84 \\
5 & 17 & 67.12 & 10.93 & Acceptable & 84 \\
6 & 14 & 59.09 & 10.99 & Acceptable & 74 \\
7 & 13 & 68.38 & 6.04 & Competent & 85 \\
8 & 10 & 69.00 & 6.94 & Competent & 86 \\
9 & 31 & 69.94 & 6.19 & Competent & 87 \\
10 & 17 & 68.00 & 5.83 & Competent & 85 \\
\hline
\end{tabular}

\section{Discussion}

This study examined the development and validation of the ANSI and the preservice teachers' self-assessment of their competence in achieving the NASPE beginning teacher standards. Discussion of the results is organized into three categories: (a) validation of the instrument, (b) self-assessment of competence in achieving the standards, and (c) implication for teacher education and future study.

\section{Validation of the Instrument}

In this study, the three sub-scales (factors) of the ANSI reflect the theoretical constructs underlying the NASPE beginning teacher standards. The NASPE 
beginning teacher standards articulate knowledge, skills, and dispositions in 10 essential areas that beginning teachers should possess, demonstrate, and value as a result of learning to teach from a quality teacher education program. The three subscales of the ANSI include Dispositions of Pedagogy, Pedagogical Knowledge and Skills, and Knowledge, Abilities, and Dispositions of Subject Matter. The three subscales not only embody the essential areas addressed in the standards, but also reflect the essential constructs of the standards. The three sub-scales (factors) are also supported by the correlation coefficients of the ANSI that indicate the uniqueness of each factor in relation to achieving the standards.

The three-factor solution extracted from the principal component analysis also lends a support to research on teaching. Researchers claim that quality learning and effective teaching rest with how deeply teachers grasp the content, how well teachers understand children's feelings about and thinking of learning, and how broadly teachers know a variety of instructional strategies and relevant technologies (Darling-Hammond \& Ball, 2004; Shulman, 1986, 1987; Rovegno, 1998). However, acquisition of content and pedagogical knowledge does not guarantee the effective use of knowledge in practice.

Quality learning and effective teaching, therefore, depends on how competently teachers can act with their knowledge in the classroom, how effectively teachers are able to transfer their knowledge of content and pedagogy to actual teaching situations, and how successfully teachers demonstrate abilities to teach content to students for understanding. These teaching skills and abilities are the powerful threads connecting the teacher's knowledge base with his/her teaching practices (Darling-Hammond \& Ball, 2004; Shulman, 1986, 1987; Rovegno, 1998).

Although knowledge and skills are crucial to effective teaching, they do not guarantee that teachers accomplish the core task of teaching. Teachers' beliefs and values about teaching and learning directly influence the ways teachers teach content to students. So, the effectiveness of teaching also relies on how responsibly teachers commit to deepening their subject expertise and honing their pedagogical skills, how devotedly teachers seek to understand their students, and how strongly teachers are willing to help their students to achieve the content standards. Knowledge, skills, and dispositions are all essential ingredients contributing to effective teaching (DarlingHammond \& Ball, 2004; Shulman, 1987).

Consistent with the findings described above, the correlation coefficients of the three factors of the ANSI reveal the moderately strong relationship among the three sub-scales and strong relationship between each of the sub-scales and the total scale of the ANSI. The results confirm that the three factors are interrelated to each other although each represents a distinct aspect of competence in achieving the standards. Furthermore, each of the three factors plays a critical role in contributing to overall achievement of the standards. Therefore, the factorial structure of the ANSI captures the essential constructs of the standards and also reflects the relationship among the essential constructs of the standards. The results suggest that the ANSI provide reliable and valid information about discerning pre-service teachers' self-assessment of competent levels in achieving the beginning teacher standards.

\section{Self-Assessment of Competence in Achieving the Standards}

The ANSI provides diagnostic information about the pre-service teachers' selfassessment of their overall competence in achieving the standards as a whole. First, 
based on the results of the percentage quantification, each group's self-assessment of competence in achieving the standards is ranked as the following order: (1) Group 9, (2) Group 7, (3) Group 4, (4) Group 2, (5) Group 8, (6) Group 5, (7) Group 3, (8) Group 10, (9) Group 1, and (10) Group 6. It is promising that seven groups reach the Competent Level, while only three groups belong to the Acceptable Level in achieving the beginning teacher standards based on their self-assessment. Second, the results of the mean scores and the percentage quantification reveal that the preservice teachers in Group 9, 7, 4, and 2 rate their achieving the standards significantly higher than those in Group 6. The results of the mean scores of the total scale are consistent with the results of the percentage quantification. So, the results not only differentiate group differences in overall competence in achieving the standards, but also discern differences of competency levels within the continuum from unacceptable to competent levels. The study suggests that the ANSI is the valuable instrument for assessing pre-service teachers' self-assessment of their overall competence in achieving the standards. The ANSI also provides information about competency levels of achieving the standards.

The mean scores of the three factors of the ANSI between groups provide further discernable information about what aspects of knowledge, skills, and dispositions pre-service teachers feel well prepared or ill prepared. On the first sub-scale, Dispositions of Pedagogy, all groups self-rate their preparedness for this dimension at Competent Level, except for group 6 at Acceptable Level. Group 9 self-rates their competent level on this sub-scale significantly higher than Group 6, while the rest of the comparisons are found no significant difference. Compared to Group 6, the pre-service teachers in nine teacher education programs feel that they are well prepared with positive dispositions of pedagogy. The pre-service teachers in the nine groups self-report that (a) they highly value the importance of understanding of students' differences in skills, developmental levels, and cultural values; (b) they strongly believe that planning plays critical roles in their teaching; (c) they stress the crucial role of class management in creating productive learning environment and facilitating students learning; and (d) they are willing to self-reflect on their own teaching. Supporting the study by Darling-Hammond et al. (2002), the results of this study suggest that pre-service teachers' dispositions of pedagogy can be shaped and enhanced by teacher education programs, although this study does not examine how teacher education programs change their pre-service teachers' beliefs about teaching. In contrast, the pre-service teachers in Group 6 rate their dispositions of pedagogy at the Acceptable Level. The result suggests that the teacher education program needs to better prepare their pre-service teachers with beliefs about teaching.

On the second sub-scale, Pedagogical Knowledge and Skills, four groups (Group 2, Group 4, Group 5, and Group 9) are at Competent Level, while the other six groups (Group 1, Group 3, Group 6, Group 7, Group 8, and Group 10) are at Acceptable level. Group 5 and Group 9 rank the top on assessment of this sub-scale. The followup comparisons indicate that Group 5 and Group 9 rate themselves significantly higher than Group 6. The pre-service teachers at the Competent Level self-report that they are better prepared for pedagogical knowledge such as knowledge of students, class management, motivation, planning and instructional strategies, and assessment. The pre-service teachers at the Competent Level also perceive that they possess the pedagogical skills necessary to implement their knowledge of pedagogy into teaching practices. The reason for the pre-service teachers' rating themselves one level higher 
than the pre-service teachers' rating in the other six groups might be associated with their pedagogical preparation, especially teaching experiences. At the time of this study, except for Group 5 (all student teachers), the pre-service teachers in Group 2, $4, \& 9$ indicate that their teacher education programs offer sequential course-linked practicum experiences prior to student teaching experiences. The results lend support to studies by Darling-Hammond et al. (2002) and by Laczko-Kerr \& Berliner (2002) who claim that field experiences along with student teaching experiences provide pre-service teachers with practical opportunities to apply what they have learned to teaching situations. They report that the teachers who have extensive teachingrelated clinical experiences rate their pedagogical knowledge and skills significantly higher than the teachers lacking such teaching preparation. The results of this study confirm the assertion that pedagogical skills can be acquired and enhanced when pre-service teachers have opportunities to teach content to students in a teaching context. Field experiences and student teaching experiences are powerful tools for preparing pre-service teachers with pedagogical knowledge and skills (DarlingHammond, 2000; Laczko-Kerr \& Berliner, 2002). The results also suggest that the pre-service teachers in the other six groups (at Acceptable level) need to strengthen their pedagogical knowledge and skills through involving the pre-service teachers in more field-based practicum experiences before student teaching.

On the third sub-scale, Knowledge, Ability, and Dispositions of Subject Matter, the pre-service teachers in Groups 2, 3, 7, 8, 9, and 10 rate themselves at the Competent Level, while those in Groups 1, 3, 4, and 5 are at the Acceptable Level. Group 3 and Group 9 rate themselves significantly higher than Group 6. The preservice teachers at the Competent Level feel that they have a better understanding of the relationship between physiology, anatomy, and neuromuscular structures of the human body and physical activities. They have knowledge of physical education content, critical elements of a variety of sports and physical activities, bioscience concepts related to fitness and wellness. They are knowledgeable about game rules and strategies related to individual and team sports. They perceive that they demonstrate competence in performing motor skills and physical activities and have the ability to break the content down in developmentally appropriate progressions. Also, they report that they are seeking to expand their knowledge of physical education content and to keep abreast of new ideas in physical education content. They believe that physical education plays an important role in contributing to overall health of individuals. The promising results might be related to the preservice teachers' subject matter preparation. The pre-service teachers in these groups indicate that they have taken subject matter courses such as teaching-related individual and team sports, teaching-related activities, elementary and secondary methods courses, curriculum and instruction. In contrast, the pre-service teachers at the Acceptable Level report that they have not taken some of the core subject matter courses at the time of this study. In concert with the studies by DarlingHammond et al. (2002) and Laczko-Kerr \& Berliner (2002), the results suggest that comprehensive and sequential subject matter courses in which content and contentspecific pedagogy are blended together better equip pre-service teachers with knowledge of and competence in the subject matter.

In short, the pre-service teachers in Group 9 and Group 2 self-assess themselves on all three sub-scales at the Competent Level. Conversely, the pre-service teachers in Group 6 self-assess their competence in three factors at the Acceptable Level. The other groups are at the Competent Level on two of the three sub-scales. 
Examination of differences of the three sub-scales of the ANSI between groups provides discernable information about which key component(s) of effective teaching the pre-service teachers feel better prepared for, well prepared for, or in need of improvement. Even though the pre-service teachers in Groups 3, 4, 5, 7, and 8 self-assess their overall achievement of the standards at the Competent Level, this does not mean that their competence in three key factors all reaches the Competent Level.

\section{Implication for Teacher Education and Future Study}

Examining pre-service teachers' self-assessment of their competence in achieving the beginning teacher standards provides insightful information about the preservice teachers' sense of their preparation for being qualified teachers in the future. One of the purposes in teacher education programs is to promote pre-service teachers' self-efficacy about their ability to achieve the core teaching tasks. DarlingHammond et al. (2002) reports that teachers' self-efficacy about their ability to teach is significantly associated with their attitudes toward the teaching profession and values about teaching. Further, Darling-Hammond (2000) and DarlingHammond \& Ball (2004) confirm that teachers who feel better prepared for subject matter and pedagogy tend to seek continual professional growth and development, compared to teachers who perceive they are under-qualified for teaching content to students in context. Thus, enhancing pre-service teachers' competence in achieving the standards is critical to teacher education programs although assessing competent levels of achieving the standards cannot just be based on pre-service teachers' sense of their achieving the standards.

The focus of this study on the pre-service teachers' self-assessment of their competence in three key factors of achieving the standards also provides teacher educators with diagnostic information about which key aspects their pre-service teachers feel themselves as competent or incompetent level. On the other hand, the pre-service teachers' sense of their competence in achieving the standards provides teacher educators with feedback about the effectiveness of their teacher education programs. The feedback may help teacher educators reflect on their existing curricula in relation to the beginning teacher standards. The information may be conducive to teacher educators examining which aspect of preparation their preservice teachers' self-assessing themselves are incompetent from the pre-service teachers' perspectives in order to revamp their teacher education programs in alignment with the beginning teacher standards.

This study also suggests that the ANSI can be used as a self-reflective tool for pre-service teachers to self-evaluate their competent levels in terms of content knowledge and ability, pedagogical knowledge and skills, and dispositions. Once Pre-service teachers complete the ANSI, they may use the results of sub-scales of ANSI in this study to calculate their scores on each sub-scale. Subsequently, they may compare the scores with the Burry-Stock's methods of percentage requirement to self-evaluate the extent to which they achieve the beginning teachers standards in terms of Competent Level (85-99\%), (b) Acceptable Level (70-84\%), (c) Developing Level (35-69\%), and (d) Unacceptable Level (1-34\%). This may help pre-service teachers learn how to apply the research results into the process of selfevaluation and how to self-reflect on their own knowledge, teaching, and dispositions based on the validated instrument. The information may help them 
recognize which key aspects of effective teaching they need to improve on and to maintain in order to guide their future learning.

This study examines the teachers' self-assessment of their competence in achieving the standards instead of direct observation of the teachers' teaching and examination of their performance-based documents. Their perceptions of achieving the standards are not equal to the actual performance levels they demonstrate through learning how to teach. To examine pre-service teachers' achievement of the standards from a performance perspective, future studies need to combine the inventory with the assessment of pre-service teachers' teaching using observational instruments, evaluation of their teaching portfolios, and/or their written exams on the subject matter and pedagogy courses. In that way, the studies will provide comprehensive and holistic information about pre-service teachers' competence in achieving the standards. The research Findings will serve as a guide for teacher educators to discern and reflect on how to effectively prepare their pre-service teachers for achieving the standards in order to ensure high quality learning for students.

Acknowledgments I would like to express my sincere appreciation to Wei Bian, Ang Chen, Donetta Cothran, Grace Goc Karp, Ron McBride, Bryan McCullick, Debora Tannehill, Bonnie Tjeerdsma, and Phillip Ward for their supports and their students' participation in this study. Please address all correspondence concerning this article to Weiyun Chen, Division of Kinesiology, University of Michigan, Ann Arbor, MI 48109.

\section{References}

Blank, R. K. (2002). Using surveys of enacted curriculum to advance evaluation of instruction in relation to standards. Peabody Journal of Education, 77(4), 86-121.

Burry-Stock, J. A. (1995). Expert Science Teaching Evaluation Model (ESTEEM): Theory, development, and research. Kalamazoo, MI: The Evaluation Center, Western Michigan University.

Chen, W., \& Rovegno, I. (2000). Examination of expert and novice teachers' constructivist-oriented teaching practices using a movement approach to elementary physical education. Research Quarterly for Exercise and Sport, 71, 357-372.

Darling-Hammond, L. (2000). Teacher quality and student achievement: A review of state policy evidence. In Education policy analysis archives 8(1). Retrieved January 20, 2004, from http:// www.epaa.asu.edu/epaa/v8n1/

Darling-Hammond, L. (2001). Standard setting in teaching: Changes in licensing, certification, and assessment. In V. Richardson (Ed.), Handbook of research on teaching, 4th edn (pp. 751-776). Washington, D.C.: American Educational Research Association.

Darling-Hammond, L., \& Ball, D. L. (2004). Teaching for high standards: What policymakers need to know and be able to do. Kutztown, PA: National Commission on Teaching and America's Future.

Darling-Hammond, L., Chung, R., \& Frelow, F. (2002). Variation in teacher preparation: How well do different pathways prepare teachers to teach? Journal of Teacher Education, 53(4), 286-302.

Delandshere, G., \& Arens, S. A. (2001). Representations of teaching and standards-based reform: Are we closing the debate about teacher education? Teaching and Teacher Education, 17, 547566.

Delandshere, G., \& Petrosky, A. (2004). Political rationales and ideological stances of the standardsbased reform of teacher education in the US. Teaching and Teacher Education, 20, 1-15.

Goldhaber, D. D., \& Brewer, D. J. (2000). Does certification matter? High school teacher certification status and student achievement. Educational Evaluation and Policy Analysis, 22(2), 129-145.

Hammrich, P. L. (1998). What the Science Standards say: Implications for teacher education. Journal of Science Teacher Education, 9, 165-186.

Hastie, P. A., \& Vlaisavljevic, N. (1999). The relationship between subject-matter expertise and accountability in instructional tasks. Journal of Teaching in Physical Education, 19, 22-33.

Ge Springer 
Hinkle, D. E., Wiersma, W., \& Jurs, S. G. (1994). Applied statistics for the behavioral science. Dallas, TX: Houghton Mifflin.

Laczko-Kerr, I., \& Berliner, D. C. (2002). The effectiveness of "teach for America" and other undercertified teachers on student academic achievement: A case of harmful public policy. Education Policy Analysis Archives, 10(37). Retrieved January 20, 2004 from http://www.epaa.asu.edu/ epaa/v10n37/

Monk, D. (1994). Subject area preparation of secondary mathematics and science teachers and student achievement. Economics of Educational Review, 12(2), 125-142.

Mullens, J. (1998). Validating teacher response on instructional practice self-report surveys: Findings from a recent field-test. Prepared for the Association for Public Policy Analysis and Management Research Conference, New York City.

NASPE. (1995). National Standards for Beginning Physical Education Teachers. Reston, VA: NASPE/AAHPERD.

NASPE. (2003). National Standards for Beginning Physical Education Teachers, 2nd edn. Reston, VA: NASPE/AAHPERD.

Shulman, L. S. (1986). Those who understand: Knowledge growth in teaching. Educational Researcher, 15(2), 4-14.

Shulman, L. S. (1987). Knowledge and teaching: Foundations of the new reform. Harvard Educational Review, 57, 1-22.

Rovegno, I. (1998). The development of in-service teachers' knowledge of a constructivist approach to physical education: Teaching beyond activities. Research Quarterly for Exercise and Sport, 69, $147-162$.

Walkwitz, E., \& Lee, A. (1992). The role of teacher knowledge in elementary physical education instruction: An exploratory study. Research Quarterly for Exercise and Sport, 63, 179-185.

Wilson, S. M., Floden, R. E., \& Ferrini-Mundy, J. (2001). Teacher preparation research: Current knowledge, gaps, and recommendations. Seattle, WA: University of Washington, Center for the Study of Teaching and Policy. 